\title{
Interrelations Between Two Pathways of Methionine Biosynthesis in Aerobacter aerogenes
}

\author{
By J. F. MORNINGSTAR, JUn. AND R. L. KISLIUK \\ Department of Pharmacology, Tufts University School of Medicine, \\ Boston, Massachusetts, U.S.A.
}

(Received 9 October 1964)

\begin{abstract}
SUMMARY
Two pathways for methionine methyl formation, one cobalamindependent and one cobalamin-independent, corresponding to those observed in Escherichia coli PA 15 have been found in Aerobacter aerogenes. An initial difficulty in showing the cobalamin-dependent pathway in cellfree extracts proved to be due to the presence of enzymes which caused the removal of adenosylmethionine, a cofactor required for this system. In contrast to $\boldsymbol{E}$. coli PA 15, A. aerogenes contains holocobalaminmethyltransferase even when grown in the absence of cobalamin. When cobalamin is added to the growth medium, the cobalamin-independent pathway is repressed.
\end{abstract}

\section{INTRODUCTION}

Escherichia coli has two enzymic mechanisms of methyl group transfer from 5-methyltetrahydropteroylglutamate derivatives to homocysteine to form methionine (Woods, Foster \& Guest, 1964). A major difference in these two pathways is that one shows a requirement for a cobalamin derivative and the other does not (Kisliuk \& Woods, 1960; Kisliuk, 1961). The cobalamin-requiring system also requires reduced flavin adenine dinucleotide and adenosylmethionine as cofactors (Rosenthal \& Buchanan, 1963; Buchanan et al. 1964). Either 5-methyltetrahydropteroyltriglutamate or 5 methyltetrahydropteroylglutamate can serve as methyl donor. The cobalamin-independent pathway does not require adenosylmethionine or reduced flavin adenine dinucleotide and will utilize only 5-methyltetrahydropteroyltriglutamate as methyl donor (Guest, Friedman \& Foster, 1962).

To demonstrate the cobalamin-dependent system the vitamin must be added to the growth medium or to enzymic extracts. Lacking a cobalamin supplement, Escherichia coli PA 15 does not synthesize detectable holocobalaminmethyltransferase (Kisliuk, 1961) although apoenzyme is readily demonstrable (Guest, Friedman, Dilworth \& Woods, 1964). A role for cobalamin has not as yet been established for any reaction in $E$. coli other than methionine biosynthesis. Aerobacter aerogenes was selected for further study because this organism has been shown to require a cobalamin derivative for the dioldehydrase reaction (Lee \& Abeles, 1963). The relative amounts of methionine synthesis were determined under various conditions of growth. 


\section{METHODS}

Organisms. The strain of Aerobacter aerogenes (ATCC 8724) used in these studies was the same organism as used to study the cobamide coenzyme requiring dioldehydrase reaction (Lee \& Abeles, 1963). Escherichia coli PA 15 is an auxotroph which requires serine or glycine for growth.

Growth conditions. The glucose inorganic salts medium of Davis \& Mingioli (1950) was used for the growth of Aerobacter aerogenes. This medium was supplemented with $4 \mu \mathrm{g}$. cobalamin/l. when cobalamin-grown organisms were required. Growth was aerobic for $17 \mathrm{hr}$ at $37^{\circ}$. The inoculum was $10 \mathrm{ml}$. of a $24 \mathrm{hr}$ culture per $15 \mathrm{l}$. medium. The organisms were harvested in a refrigerated Sharples centrifuge.

Escherichia coli was grown in the same way except that the medium was supplemented with glycine $(0 \cdot 8 \mathrm{~g} . / 1$.$) .$

The organisms were maintained on agar slopes prepared from the media indicated.

Preparation of extracts. Acetone-dried organisms were prepared and extracted as described by Kisliuk \& Woods (1960) except that $1 \mathrm{~g}$. dried organisms were extracted with $20 \mathrm{ml}$. water and the extracts were not dialysed. Sonic extracts were prepared and fractionated as described by Kisliuk (1961).

The Escherichia coli holocobalaminmethyltransferase used in the present work was an ammonium sulphate fraction (0-35\% saturation) of a sonic extract of cobalamin-grown organisms (Kisliuk, 1961) containing $16 \mathrm{~m} \mu \mathrm{g}$. cobalamin/mg. protein. An amount of material containing $22 \mathrm{~m} \mu \mathrm{g}$. cobalamin was added to each incubation mixture where indicated.

Conditions for methionine synthesis in enzyme extracts. The standard reaction mixture used to study the overall formation of methionine from serine and homocysteine via 5-methyltetrahydrofolate consists of diphosphopyridine nucleotide $5 \times 10^{-4} \mathrm{M}$, adenosine triphosphate $5 \times 10^{-3} \mathrm{M}$, pyridoxal phosphate $5 \times 10^{-4} \mathrm{M}$, fructose-1,6-diphosphate $5 \times 10^{-3} \mathrm{M}, \mathrm{MgSO}_{4} 5 \times 10^{-3} \mathrm{M}, \quad$ L-serine $5 \times 10^{-3} \mathrm{M}, \mathrm{DL}$ homocysteine $10^{-2} \mathrm{M}$, potassium phosphate $(\mathrm{pH} 7 \cdot 8) 7 \cdot 5 \times 10^{-2} \mathrm{M}$.

The reaction mixtures ( $2 \mathrm{ml}$. final volume) were incubated for $4 \mathrm{hr}$ at $37^{\circ}$ in Thunberg tubes filled with hydrogen. The reaction was stopped by placing the tubes in a boiling water bath for 3 min. After centrifuging down the precipitate, the supernatant fluid was assayed for methionine

Assays. L-Methionine was determined microbiologically with Leuconostoc mesenteroides (ATCC 8042) by using Difco methionine assay medium. Cobalamin was determined with Lactobacillus leichmannii (ATCC 7830) by using Difco $\mathbf{B}_{12}$ assay medium. The thymidine content of all samples was negligible as determined after destroying cobalamin by autoclaving samples in $0.2 \mathrm{~N}-\mathrm{NaOH}$ for $30 \mathrm{~min}$.

Protein was determined spectrophotometrically (Layne, 1957).

Materials. Adenosine triphosphate, diphosphopyridine nucleotide, flavin adenine dinucleotide and fructose-1,6-diphosphate were products of the Sigma Chemical Company. S-Adenosyl-L-methionine iodide was obtained from the California Corporation for Biochemical Research. Pteroyltriglutamic acid was supplied by Lederle Laboratories through the courtesy of Dr T. H. Jukes. Tetrahydropteroylglutamic acid was prepared by catalytic reduction (Kisliuk, 1957). Tetrahydropteroyltriglutamate was prepared similarly except that $10 \mathrm{mg}$. were reduced with 
$10 \mathrm{mg}$. catalyst in $10 \mathrm{ml}$. glacial acetic acid. After removal of the catalyst by filtration under hydrogen the acetic acid was removed by lyophilization.

\section{RESULTS}

Methionine synthesis by bacterial suspensions

Suspensions of Aerobacter aerogenes and Escherichia coli PA 15 were tested for their ability to synthesize methionine from homocysteine, with serine as the precursor of the methyl group under conditions similar to those described by Gibson \& Woods (1960). These workers observed that cobalamin added to suspensions of organisms grown in the absence of cobalamin stimulated methionine synthesis. When cobalamin was included in the growth medium, the harvested organisms no longer were stimulated by its addition (Table 1). Suspensions of organisms grown in the absence of cobalamin synthesized considerably more methionine when cobalamin was added to the suspending medium than did the corresponding cobalamin-grown organisms. This suggests that when the cobalamin-dependent pathway operates maximally during growth the cobalamin-independent pathway is repressed. When cobalamin was added to suspensions of organisms grown in its absence, it probably combined with apocobalaminmethyltransferase present in the organisms, thus enabling them to synthesize methionine by both pathways simultaneously. The results given in Table 1 are in agreement with the conclusion of Rowbury \& Woods (1961) that substances which enhance methionine synthesis during growth decrease the ability of suspended organisms to synthesize this amino acid.

Table 1. Methionine synthesis by suspensions of Aerobacter aerogenes and Escherichia coli

The suspending medium consisted of potassium phosphate, (pH 7.4), 0.1 M; DLhomocysteine, $0.01 \mathrm{M}$; D-glucose, $0.02 \mathrm{M}$; and where indicated L-serine, $0.005 \mathrm{M}$; cobalamin $7 \times 10^{-6} \mathrm{M}$. The organisms added were equivalent to $7 \mathrm{mg}$. dry weight $/ \mathrm{ml}$. Incubated at $37^{\circ}$ for $3 \mathrm{hr}$.

$\begin{gathered}\text { Addition to } \\ \text { suspension }\end{gathered}$
$\begin{gathered}\text { Growth } \\ \text { without } \\ \text { cobalamin }\end{gathered}$ $\begin{gathered}\begin{array}{c}\text { Growth } \\ \text { with } \\ \text { cobalamin }\end{array} \\ \text { organism })\end{gathered}$

(1) Aerobacter aerogenes

$\begin{array}{lrr}\text { None } & \mathbf{6 \cdot 2} & 10 \cdot 2 \\ \text { L-serine } & \mathbf{7 \cdot 4} & \mathbf{2 5 \cdot 4} \\ \text { L-serine + cobalamin } & \mathbf{3 6 \cdot 0} & \mathbf{2 2 \cdot 6}\end{array}$

(2) Escherichia coli

$\begin{array}{lrr}\text { None } & 2 \cdot 4 & 2 \cdot 9 \\ \text { L-serine } & 11 \cdot 7 & 13 \cdot 1 \\ \text { L-serine + cobalamin } & 20 \cdot 3 & 14 \cdot 4\end{array}$

Methionine synthesis by extracts of Aerobacter aerogenes

With extracts of acetone-dried Aerobacter aerogenes grown in the absence of cobalamin, substantial synthesis of methionine occurred, this synthesis being inhibited by the addition of tetrahydropteroylglutamate ('Table 2). However, this 
inhibition was not annulled by the addition of cobalaminmethyltransferase as it is in the corresponding Escherichia coli PA 15 system (Kisliuk, 1961). With extracts of cobalamin-grown Aerobacter aerogenes, methionine synthesis was very small and was further suppressed by tetrahydropteroylglutamate. This again contrasts with the situation in Escherichia coli PA 15 where methionine synthesis in extracts of cobalamin-grown organisms was not inhibited by tetrahydropteroylglutamate (Kisliuk \& Woods, 1960). These results are consistent with the suggestion above that the presence of cobalamin in the growth medium repressed the cobalaminindependent pathway. Earlier evidence obtained with $E$. coli PA 15 (Kisliuk \& Woods, 1960) on the effect of cobalamin in the growth medium in depressing methionine synthesis in extracts may be interpreted in the same manner. Cobalaminmethyltransferase, although present, was not active in extracts of Aerobacter aerogenes under the conditions used for Table 2 (see below).

\section{Table 2. Inhibition of methionine synthesis by tetrahydropteroylglutamate}

The standard reaction mixture was incubated with extracts of Aerobacter aerogenes prepared from acetone-dried organisms grown without or with added cobalamin (3.5 $\mathrm{mg}$. protein/incubation in each case). Tetrahydropteroylglutamate $1.8 \times 10^{-4} \mathrm{M}$.

\section{Extract of}

(1) A. aerogenes grown without cobalamin

(2) $A$. aerogenes grown with cobalamin

\section{Additions to}

reaction mixture

None

+ tetrahydropteroylglutamate

+ tetrahydropteroylglutamate

and $\boldsymbol{E}$. coli cobalaminmethyltransferase

None

+ tetrahydropteroylglutamate
L-Methionine ( $\mu$ mmoles)

300

0

$\mathbf{0}$

20

0

Table 3. Requirements for methionine synthesis by Aerobacter aerogenes extracts

The complete system consisted of the standard reaction mixture supplemented with flavin adenine dinucleotide and tetrahydropteroyltriglutamate (both $1 \times 10^{-4} \mathrm{M}$ ). An extract of acetone-dried $A$. aerogenes (grown in the absence of cobalamin) treated with Sephadex G-50 was used as a source of enzyme (3.8 $\mathrm{mg}$. protein added).

$\begin{array}{lc} & \begin{array}{c}\text { L-Methionine } \\ (\mu \text { mmoles })\end{array} \\ \text { Complete system } & 160 \\ \text { Minus serine } & 10 \\ \text { Minus homocysteine } & 0 \\ \text { Minus tetrahydropteroyltriglutamate } & 55 \\ \text { Minus DPN } & 115 \\ \text { Minus ATP } & 160 \\ \text { Minus fructose-1,6-diphosphate } & 35 \\ \text { Minus pyridoxal phosphate } & 40 \\ \text { Minus Mg2+ } & 60 \\ \text { Minus flavin adenine dinucleotide } & 145\end{array}$

\section{Requirements for methionine synthesis in Aerobacter aerogenes}

Extracts of acetone-dried Aerobacter aerogenes (grown in the absence of cobalamin) when treated with Sephadex G-50 (Kisliuk, 1960) and supplemented with all the required cofactors except a folate derivative, showed a negligible methionine 
synthesis (Fig. 1). As observed with Escherichia coli PA 15 (Kisliuk \& Woods, 1960) tetrahydropteroylglutamate did not promote methionine synthesis but tetrahydropteroyltriglutamate did reactivate the system (Jones, Guest \& Woods, 1961). The additional requirements for the $A$. aerogenes system are shown in Table 3. In this experiment an absolute requirement was observed only for the substrates serine and homocysteine. The extract was only partially depleted of tetrahydropteroyltriglutamate, diphosphopyridine nucleotide, fructose-1,6-diphosphate, pyri-

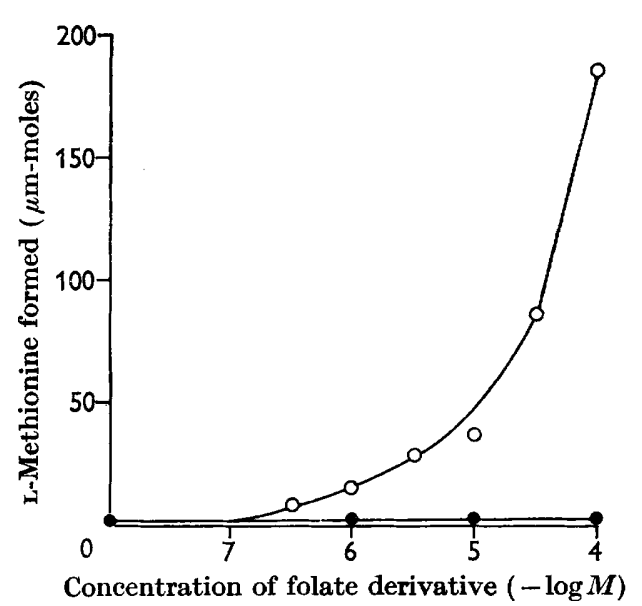

Fig. 1

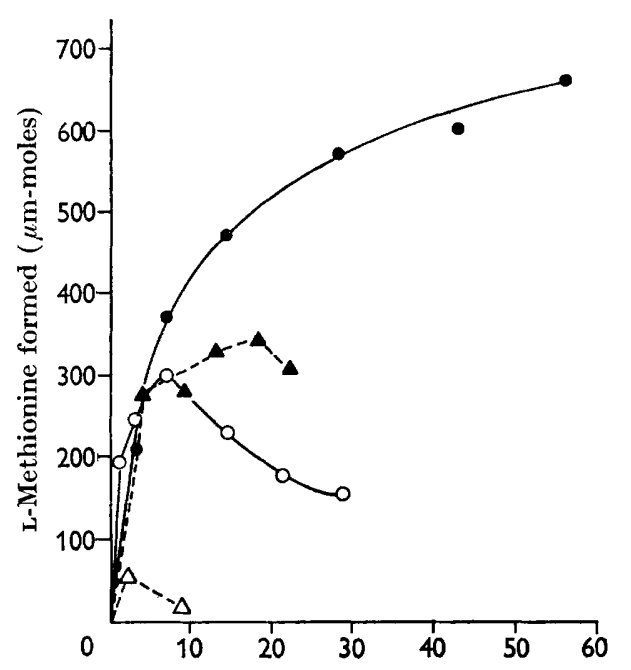

Cobalaminmethyltransferase ( $\mu \mathrm{g}$ cobalamin)

Fig. 2

Fig. 1. The effect of reduced folate derivatives on methionine synthesis in Sephadextreated extracts of Aerobacter aerogenes. The standard reaction mixture was incubated with Sephadex-treated extracts of acetone-dried $A$. aerogenes grown in the absence of cobalamin $\left(3.8 \mathrm{mg}\right.$. protein) for $4 \mathrm{hr}$ at $37^{\circ}$ in a total volume of $2 \mathrm{ml}$. dropteroylglutamate; $\mathrm{O}-\mathrm{O}$, tetrahydropteroyltriglutamate.

Fig. 2. Assay of fractions of Aerobacter aerogenes grown in the presence of cobalamin for cobalaminmethyltransferase activity. Assay conditions are the same as described in Table 5 with Escherichia coli cobalamin enzyme omitted. $\bigcirc-0$, fraction 14; -0 , fraction 14 plus $7 \cdot 5 \times 10^{-5} \mathrm{M}$. adenosylmethionine; $\triangle-\triangle$, fraction $15 ; \Delta-\Delta$, fraction 15 plus $7.5 \times 10^{-5} \mathrm{M}$ adenosylmethionine.

doxal phosphate, $\mathrm{Mg}^{2+}$ and flavin adenine dinucleotide. A requirement for adenosine triphosphate would not be expected since the cobalamin-independent pathway proceeds without this cofactor (Guest et al. 1962).

\section{Inhibition of the cobalaminmethyltransferase reaction by extracts of Aerobacter aerogenes}

When extracts of Aerobacter aerogenes and Escherichia coli PA 15 were mixed under conditions appropriate for the expression of the cobalamin-independent pathway (Table 4, part $(a)$ ) methionine synthesis occurred. When cobalaminmethyltransferase was added (Table 4, part $(b)$ ) to $E$. coli extracts, methionine synthesis was greatly stimulated, probably because both pathways were operating simultaneously. There was no corresponding stimulation in $A$. aerogenes extracts nor in a 
mixture of $A$. aerogenes and $E$. coli PA 15 extracts. The cobalaminmethyltransferase was apparently inactive in the presence of $A$. aerogenes extracts. This suggestion is substantiated by the results obtained under conditions where the cobalaminindependent pathway was inhibited and only the cobalamin dependent pathway operates, i.e. in the presence of tetrahydropteroylglutamate (Table 4, part (c)). The addition of $A$. aerogenes extract under these conditions greatly decreased methionine synthes is.

Table 4. The effects of extracts of Aerobacter aerogenes on methionine synthesis by Escherichia coli extracts

The standard reaction mixture was incubated with extracts of acetone-dried $A$. aerogenes on $E$. coli (grown in the absence of cobalamin) 5.3 and $4.2 \mathrm{mg}$. protein per incubation, respectively. When the extracts were combined half of each amount was added. Tetrahydropteroylglutamate $1.8 \times 10^{-4} \mathrm{M}$ where indicated.

Type of extract

(a) E. coli

A. aerogenes

E. coli $+A$. aerogenes

(b) E. coli

A. aerogenes

E. coli $+A$. aerogenes

(c) E. coli

E. coli

E. coli + A. aerogenes
Additions

None
None
None
$E$. coli cobalaminmethyltransferase
$E$. coli cobalaminmethyltransferase
$E$. coli cobalaminmethyltransferase
Tetrahydropteroylglutamate
Tetrahydropteroylglutamate $+E$. coli
cobalaminmethyltransferase
Tetrahydropteroylglutamate $+E$. coli
cobalaminmethyltransferase

None

None

L-Methionine ( $\mu$ mmoles)

450

300

500

1850

300

500

30

700

100

Table 5. Annulment of the inhibition of cobalaminmethyltransferase by addition of adenosylmethionine

The standard reaction mixture was incubated with extracts of acetone-dried Escherichia coli PA 15 (6 mg. protein), $E$. coli PA 15 cobalaminmethyltransferase, tetrahydropteroylglutamate $1.8 \times 10^{-4} \mathrm{M}$ and, where indicated, a sonic extract of Aerobacter aerogenes (0.66 mg. protein), adenosylmethionine $7.5 \times 10^{-5} \mathrm{M}(150 \mu \mathrm{mmoles})$, L-methionine $2.5 \times 10^{-4}$ M $(500 \mu$ mmoles $)$.

Addition

\section{None}

Adenosylmethionine

$A$. aerogenes extract

Adenosylmethionine $+A$. aerogenes extract

Adenosylmethionine $+A$. aerogenes extract minus L-serine

$A$. aerogenes extract + L-methionine

$$
\text { L-Methionine }
$$

( $\mu$ mmoles)

250
250
30
200
30
550

\section{The nature of the inhibitor in Aerobacter aerogenes extracts}

When extracts of Aerobacter aerogenes were heated for $5 \mathrm{~min}$. at $100^{\circ}$ they were no longer inhibitory, suggesting that the inhibitor is an enzyme. It was considered that the inhibition might be due to enzymic removal of methionine; however, this appeared not to be the case since added methionine was recovered at the end of the incubation (Table 5). It was then observed that the inhibition was annulled by the addition of adenosylmethionine (Table 5). It seems likely therefore that the inhibition of cobalaminmethyltransferase by $A$. aerogenes extracts was due to the ability of these extracts to metabolize adenosylmethionine which is required for this 
system in catalytic amounts. Shapiro (1962) observed that extracts of this organism metabolized adenosylmethionine by (1) methylating homocysteine to methionine and adenosylhomocysteine, and (2) decomposition to adenine, methylthioribose and homoserine. The results of Table 5 indicate that the former reaction might account for $20 \%$ of the breakdown of adenosylmethionine (30 of $150 \mu$ mmoles). The remainder was presumably destroyed by the latter reaction.

\section{Isolation of cobalaminmethyltransferase from Aerobacter aerogenes grown in the absence and presence of cobalamin}

To show conclusively the presence of cobalaminmethyltransferase in extracts of Aerobacter aerogenes, sonic extracts were fractionated with ammonium sulphate and calcium phosphate gel by the method of Kisliuk (1961). The distribution of

Table 6. Fractionation of sonic extracts of Aerobacter aerogenes

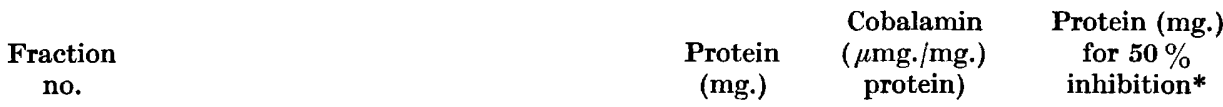

(a) Organisms grown without cobalamin

$\left(\mathrm{NH}_{4}\right)_{2} \mathrm{SO}_{4}$ fractionation:

\begin{tabular}{|c|c|c|c|}
\hline Sonic extract ( $45 \mathrm{mg}$. protein $/ \mathrm{ml}$.) & 7050 & $2 \cdot 4$ & $0 \cdot 28$ \\
\hline $0-30 \%$ saturation & 240 & $5 \cdot 5$ & $0 \cdot 12$ \\
\hline $30-40 \%$ saturation & 1560 & $\mathbf{3 \cdot 3}$ & $0 \cdot 18$ \\
\hline $\mathbf{4 0 - 5 0} \%$ saturation & 1136 & $\mathbf{3 \cdot 5}$ & $0 \cdot 15$ \\
\hline $50-60 \%$ saturation & 140 & $2 \cdot 8$ & $\mathbf{0 \cdot 2 5}$ \\
\hline $\begin{array}{l}\mathrm{a}_{3}\left(\mathrm{PO}_{4}\right)_{2} \text { gel: } \\
\left(\mathrm{NH}_{4}\right)_{2} \mathrm{SO}_{4}, 30-40 \% \text { saturation }\end{array}$ & 1190 & $3 \cdot \mathbf{3}$ & $0 \cdot 18$ \\
\hline Buffer supernatant, $0.01 \mathrm{M}$ & 35 & $1 \cdot 6$ & $0 \cdot 24$ \\
\hline Buffer supernatant, $0.05 \mathrm{M}$ & 122 & $10 \cdot 4$ & $-\dot{T}$ \\
\hline Buffer supernatant, $0 \cdot 10 \mathrm{M}$ & 171 & $\mathbf{2 \cdot 3}$ & $-\dagger$ \\
\hline Buffer supernatant, $1 \cdot 0 \mathrm{M}$ & 343 & $2 \cdot 2$ & 0.35 \\
\hline
\end{tabular}

(b) Organisms grown with cobalamin

$\left(\mathrm{NH}_{4}\right)_{2} \mathrm{SO}_{4}$ fractionation:

\begin{tabular}{|c|c|c|c|}
\hline Sonic extract (41 mg. protein $/ \mathrm{ml}$.) & 6953 & $15 \cdot 2$ & 0.25 \\
\hline $0-30 \%$ saturation & 432 & $9 \cdot 1$ & $0 \cdot 19$ \\
\hline $30-40 \%$ saturation & 1134 & $\mathbf{2 1} \cdot \mathbf{0}$ & $0 \cdot 11$ \\
\hline $40-50 \%$ saturation & 1280 & $22 \cdot 0$ & $0 \cdot 10$ \\
\hline $50-60 \%$ saturation & 304 & $15 \cdot 3$ & $0 \cdot 16$ \\
\hline $\begin{array}{l}\mathrm{a}_{3}\left(\mathrm{PO}_{4}\right)_{2} \text { gel: } \\
\left(\mathrm{NH}_{4}\right)_{2} \mathrm{SO}_{4}, 30-40 \% \text { saturation }\end{array}$ & 1134 & $21 \cdot 0$ & $0 \cdot 11$ \\
\hline Buffer supernatant, $0.01 \mathrm{M}$ & 46 & $34 \cdot 6$ & 0.18 \\
\hline Buffer supernatant, $0.05 \mathrm{~m}$ & 158 & $43 \cdot 8$ & $-\ddagger$ \\
\hline Buffer supernatant, $0 \cdot 10 \mathrm{M}$ & 110 & $15 \cdot 5$ & $-\neq$ \\
\hline Buffer supernatant, $1 \cdot 0 \mathrm{M}$ & 384 & $\mathbf{2 \cdot 7}$ & $0 \cdot 40$ \\
\hline
\end{tabular}

* To determine this value, the fraction was added at various concentrations to an assay system containing the standard reaction mixture + tetrahydropteroylglutamate $\left(1 \cdot 8 \times 10^{-4} \mathrm{M}\right)$, an extract of acetone-dried $E$. coli PA 15 (7 mg. protein) and $E$. coli PA 15 cobalaminmethyltransferase. In each case the inhibition could be annulled with adenosylmethionine.

$\dagger$ Results with these fractions are shown in Table $\%$.

$\ddagger$ Results with these fractions are shown in Fig. 2.

cobalamin in these fractions (Table 6) was similar to that obtained with cobalamingrown Escherichia coli (Kisliuk, 1961). Only fraction 6 (Table 6) appeared to be entirely free from inhibitor (Table 7). Fractions 7, 14, 15 showed inhibition which 
was annulled with adenosylmethionine (Table 7, Fig. 2). In subsequent trials fractions equivalent to fraction 14 were also obtained free from inhibitor.

Two fractions (Table 7) obtained from organisms grown in the absence of cobalamin were tested for cobalaminmethyltransferase activity (adenosylmethionine added) separately. Activity was demonstrable in both fractions, showing that holocobalaminmethyltransferase was endogenously synthesized. In other organisms so far studied, Escherichia coli (Kisliuk, 1961), pigs (Loughlin, Elford \& Buchanan, 1964) and chickens (Dickerman, Redfield, Bieri, \& Weissbach, 1964), it is formed from exogenous cobalamin.

Table 7. Assay of fractions of Aerobacter aerogenes grown in the absence of cobalamin for cobalaminmethyltransferase activity

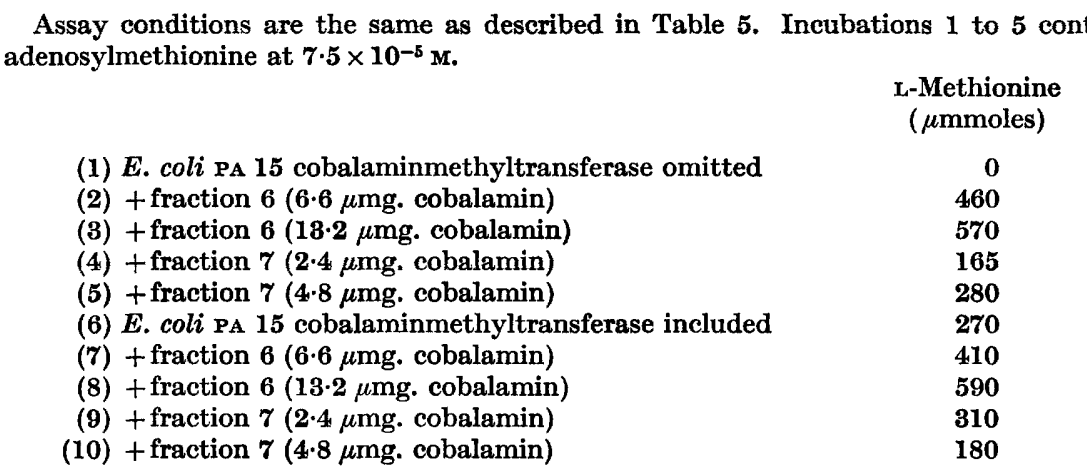

The cobalamin content of the various fractions was considerably enhanced by growth on cobalamin. However, the specific activity did not change. The m $\mu$ moles methionine formed per $\mathrm{m} \mu \mathrm{g}$ cobalamin when $5 \mathrm{~m} \mu \mathrm{g}$ cobalamin was added to the assay system was 61 for the material prepared from cobalamin grown organisms (Fig. 2) and 57 for the corresponding preparations from organisms grown in the absence of cobalamin (Table 7). The activity of the Escherichia coli preparation used in the present work ( $12 \mathrm{~m} \mu \mathrm{moles} / \mathrm{m} \mu \mathrm{g}$.) was somewhat lower because of deterioration in storage.

\section{DISCUSSION}

During this work, the late Professor D. D. Woods kindly informed us of experiments made in his laboratory in which methylcobalamin served as a methyl donor to homocysteine when incubated with extracts of Aerobacter aerogenes. This provides further evidence that cobalaminmethyltransferase is present in this organism. Although the cobalamin-dependent pathway was inactive in extracts because of removal of adenosylmethionine it apparently does function in vivo, otherwise one would not expect the observed repression of the cobalamin-independent pathway due to increased synthesis of methionine in cobalamin-grown organisms.

One of us (R.L.K.) is indebted to the Leukemia Society for a scholarship. The work was supported by a grant from the National Science Foundation (U.S.A.). We thank Mr Kenneth Skala for help with some of the experiments. 


\section{REFERENCES}

Buchanan, J. M., Elford, H. L., Loughlin, R. E., McDougald, B. M. \& Rosenthal, S. (1964). The role of vitamin $\mathrm{B}_{12}$ in methyl transfer to homocysteine. Ann. N.Y. acad. sci. $112,756$.

Davis, B. D. \& Mingroli, E. S. (1950). Mutants of Escherichia coli requiring methionine or vitamin $B_{12}$. J. Bact. $60,17$.

Dickerman, H., Redfield, B. G., Bieri, J. G. \& Weissbach, H. (1964). The role of vitamin $B_{12}$ in methionine biosynthesis in avian liver. J. biol. Chem. 239, 2545.

Gibson, F. \& Woods, D. D. (1960). The synthesis of methionine by suspensions of Escherichia coli. Biochem. J. 74, 160.

Guest, J. R., Friedman, S., Dilwonth, M. J. \& Woods, D. D. (1964). Methylcobalamin as a source of the methyl group of methionine. Ann. N.Y. Acad. Sci. 112, 774.

Guest, J. R., Friedman, S. \& Fos'ter, M. A. (1962). Alternative pathways for the methylation of homocysteine by Escherichia coli. Biochem. J. 84, 93 P.

Jones, K. M., Guest, J. R. \& Woods, D. D. (1961). Folic acid and the synthesis of methionine by extracts of Escherichia coli. Biochem. J. 79, 566 .

Kistiuk, R. L. (1957). Studies on the mechanism of formaldehyde incorporation into serine. J. biol. Chem. 227, 805.

KisLiUk, R. L. (1960). A mild procedure for separating enzymes and cofactors. Biochim. Biophys. Acta, 40, 531.

Kisliuk, R. L. (1961). Further studies on the relationship of vitamin $B_{12}$ to methionine synthesis in extracts of Escherichia coli. J. biol. Chem. 236, 817

KISLIUK, R. L. \& Woods, D. D. (1960). Interrelationships between folic acid and cobalamin in the synthesis of methionine by extracts of Escherichia coli. Biochem. J. 75, 467.

LAYNE, E. (1957). Spectrophotometric and turbidimetric methods for measuring proteins. Meth. Enzymol. 3, 451.

Lee, Jun. H. A. \& Abeles, R. H. (1963). Purification and properties of dioldehydrase, an enzyme requiring a cobamide coenzyme. J. biol. Chem. 238, 2367.

Loughlin, R. E., Elford, H. L. \& Buchanan, J. M. (1964). Enzymatic synthesis of the methyl group of methionine. VII. Isolation of a cobalamin-containing transmethylase (5-methyltetrahydrofolate-homocysteine) from mammalian liver. J. biol. Chem. 239, 2888.

Rosenthal, S. \& Buchanan, J. M. (1963). Enzymatic synthesis of the methyl group of methionine. VI. The catalytic role of S-adenosylmethionine in the enzyme system of Escherichia coli. Acta chem. scand. 17, S288.

Rowbury, R. J. \& Woods, D. D. (1961). Further studies on the repression of methionine synthesis in Escherichia coli. J. gen. Microbiol. 24, 129.

Shapiro, S. K. (1962). Utilization of S-adenosylmethionine by micro-organisms. J. Bact. 83, 169.

Woods, D. D., Foster, M. A. \& Guest, J. R. (1964). Cobalamin-dependent and -independent methyl transfer in methionine synthesis. In Symposium on Transmethylation and Methionine Biosynthesis. Chicago: The University of Chicago Press. (In press.) 